\title{
Health information exchange in Finland : Usage of different access types and predictors of paper use
}

\section{Hypponen, Hannele}

2019-02

Hypponen , H , Lumme , S , Reponen , J , Vanska , J , Kaipio , J , Heponiemi , T \& Laaveri , T 2019 , ' Health information exchange in Finland : Usage of different access types and predictors of paper use ' , International Journal of Medical Informatics , vol. 122 , pp. 1-6 . https://doi.org/10.1016/j.ijn

http://hdl.handle.net/10138/309774

https://doi.org/10.1016/j.jjmedinf.2018.11.005

unspecified

publishedVersion

Downloaded from Helda, University of Helsinki institutional repository.

This is an electronic reprint of the original article.

This reprint may differ from the original in pagination and typographic detail.

Please cite the original version. 


\title{
Health information exchange in Finland: Usage of different access types and predictors of paper use
}

\author{
Hannele Hyppönen ${ }^{\mathrm{a}}$, Sonja Lumme ${ }^{\mathrm{a}, *}$, Jarmo Reponen ${ }^{\mathrm{b}, \mathrm{c}}$, Jukka Vänskäe, Johanna Kaipio ${ }^{\mathrm{f}}$, \\ Tarja Heponiemi ${ }^{\mathrm{a}}$, Tinja Lääveri ${ }^{\mathrm{d}, \mathrm{e}}$

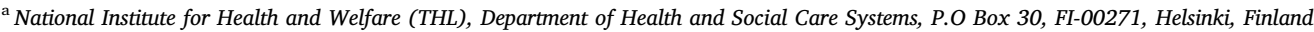 \\ ${ }^{\mathrm{b}}$ University of Oulu, Finntelemedicum, Research Unit of Medical Imaging, Physics and Technology, Oulu, Finland \\ ${ }^{\mathrm{c}}$ Hospital of Raahe, Department of Radiology, Raahe, Finland \\ ${ }^{\mathrm{d}}$ Inflammation Center, Clinic of Infectious Diseases, University of Helsinki and Helsinki University Hospital, POB 348, FI-00029, HUS, Helsinki, Finland \\ ${ }^{\mathrm{e}}$ Finnish Medical Association (FMA), Helsinki, Finland \\ ${ }^{\mathrm{f}}$ Aalto University School of Science, Department of Computer Science, Espoo, Finland
}

\section{A R T I C L E I N F O}

\section{Keywords:}

Electronic health record

Health information exchange

Communication

Physicians

Usability

Technology acceptance

\begin{abstract}
A B S T R A C T
Introduction: Timely, complete and accurate patient data is needed in care decisions along the continuum of care. To access patient data from other organizations, there are three types of regional health information exchange systems (RHIS) in use In Finland. Some regions use multiple RHISs while others do not have a RHIS available. The recently introduced National Patient Data Repository (Kanta) is increasingly used for health information exchange (HIE).

Objectives: The purpose of this study was to assess usage of paper, RHISs and Kanta by context in 2017; evolution of paper use over the years; and predictors of paper use in 2017 among Finnish physicians for HIE system development.

Methods: Data from national electronic health record (EHR) usage and user experience surveys were taken from 2010 (prior to ePrescription system implementation), 2014 (prior to implementation of Kanta) and 2017 (Kanta was in full use in the public sector and in large private organizations). The web-based surveys were targeted to all physicians engaged in clinical work in Finland.

Results: Kanta was the most frequently used means of HIE in 2017. Paper use had reduced significantly from 2010 to 2014. The trend continued in 2017. Still, up to half of the physicians reported using paper daily or weekly in 2017. There were great variations in paper use by healthcare sector, available RHIS type and EHR system used. In multivariable analysis (with all other variables constant), predictors of more frequent use of paper than electronic means for HIE were: private sector or hospital, access to Master Patient Index RHIS (type 1), multiple RHIS (type 4) or no RHIS (type 5), two particular EHR systems, older age, less experience, operative, psychiatric or diagnostic specialties, and male gender.

Conclusions: Usability of HIE systems including EHRs as access points to HIE need to be improved to facilitate usage of electronic HIE. Usage ensures more timely and complete patient data for safe, coordinated care. Specialty-specific needs and requirements call for more user participation in HIE design. Especially older professionals need training to better exploit HIS for HIE.
\end{abstract}

\section{Introduction}

Timeliness and completeness are dimensions of data quality. Access to quality data impacts all decisions made along the continuum of patient care [1]. Healthcare services are increasingly arranged in collaboration among service providers across sectors. Countries are progressing in their health information exchange (HIE) initiatives with little evidence of actual use, usability and impacts of HIE systems [2-6]. In Finland, five different regional health information systems (RHISs) have been in use for over 10 years. They have offered three different ways to access patient information with patient consent across registrars, with minor changes in user organizations over the years. Some regions use multiple RHISs while some have no RHIS available, amounting to five different RHIS types. Definitions of the types are

\footnotetext{
* Corresponding author.

E-mail addresses: Hannele.hypponen@thl.fi (H. Hyppönen), sonja.lumme@thl.fi (S. Lumme).
} 
presented in Annex 1.

A national ePrescription service was implemented between 2011-2016 in Finland to improve patient and medication safety and prescribing efficiency. Systems implemented in Sweden, Denmark, Germany, and England were used as references [7]. In 2014, the service was fully implemented in the public sector. National Patient Data Repository (Kanta) implementation started in 2014 to enhance efficient handling of patient information and patient safety. Systems implemented in Belgium, England, Netherlands, Austria, Sweden, Denmark and the United States were used as references [8]. In 2017, Kanta was in full use in the public sector and major private organizations.

According to our earlier HIE study [9], information from other organizations was available, but it was not necessarily utilized. In regions with type 2 HIE access, electronic HIE was more common than elsewhere. Primary care physicians used electronic HIE to a larger extent than physicians in specialized care. Electronic health record (EHR) brand was associated with electronic HIE usage. Moreover, users of three particular EHR brands were most active in electronic HIE use.

Usability of HIE systems is a crucial element in improving usage. Access to more complete patient data is a factor for safer, more coordinated care. Earlier studies (Annex 2) show that:

- Usage rate of HIE after implementation is often low, even if clear benefits can be shown [10]

- Usability [11-14] and practice setting [15-17] predict usage of the HIE

- Specialty, satisfaction with push HIE and improved access to complete info [17] predict overall satisfaction with HIE [15,18]

Earlier studies focus mainly on use and user satisfaction in the US. Many studies are local, focusing on intention of use. There is paucity of comprehensive, nation-wide follow-up studies comparing variation in usage of different types of HIE systems.

The objectives of this study are to assess: usage of paper, RHIS and Kanta in 2017; evolution of paper use over the years; predictors of paper use in 2017 among Finnish physicians. The study has implications on furthering usability of HIE and EHR systems, via which the HIE systems are mainly used. Good usability improves usage. Usage of timely and complete data is an important element in safe, coordinated care.

\section{Research methods}

Experiences on eHealth systems have been monitored on a regular basis in Finland from 2010 using a nationwide survey to physicians [19-22]. A web-based survey was conducted in the beginning of 2010, 2014, and 2017, targeted to all physicians aged less than 65 years of age and engaged in clinical work (https://www.laakariliitto.fi/site/assets/ files/1266/lomake_laakarit_2017.pdf). This study utilizes a combined data set including the 2010, 2014, and 2017 nationwide surveys.

The questionnaire was sent to physicians with an e-mail address in the Finnish Medical Association register. In 2010, 3929 physicians responded to survey, 3781 in 2014, and 4018 in 2017 giving response rates $27.2 \%, 23.1 \%$, and $23.4 \%$, respectively. The questionnaire from 2010 was used in all three data collections, with clarifications to some questions and pre-tested with five physicians in 2010, eight physicians in 2014 and six physicians in 2017. In this study, the outcome variable was:

Year 2017: To what extent do you use the following methods to retrieve patient information from another organization (Does not concern referrals and feedback)? 1) Papers or fax 2) RHIS (Regional Health Information System) 3) Kanta. Response alternatives: Daily, weekly, seldom, never ${ }^{1}$.

\footnotetext{
${ }^{1}$ The question about means of HIE was changed from 2010 and 2014, since
}

Year 2010 and 2014: Which of the following do you mainly use in searching for patient information from ANOTHER organization; for example, between the hospital and primary care? (Does not concern referrals and feedback) Papers, Fax; RHIS A; RHIS B; RHIS C; RHIS D; RHIS E; Other, please specify.

The controlling variables - gender, age, experience in EHR use, working sector, hospital district, HIE access type, and EHR system used - were selected based on earlier studies. HIE access type variable was generated by grouping the respondents by hospital district to 5 groups according to HIE access type implemented in each hospital district. Information on the availability of various RHISs was obtained from a separate survey [23], conducted at the same time as the physician surveys in 2010, 2014, and 2017. Respondents of nine of the most frequently used EHR systems (over 30 respondents) and a group 'Other systems' including respondents of EHR systems with less than 30 respondents were depicted in the analysis.

Representativeness was assessed by comparing age and gender distributions between respondents to the registry of the Finnish Medical Association. Overall, the target population was every year slightly younger, slightly more often male than the respondents of our survey $[19,20]$. As the differences were insignificant, the findings can be generalized to all physicians in clinical work in Finland.

The controlling variables were analyzed by year. We used the Chisquare Test to test associations between the categorical (control and outcome) variables and the Kruskal-Wallis Test for association between experience statement in EHR and year. We used multivariate logistic regression analysis to study which variables predicted physicians' use of paper in 2017. Stepwise selection method was used for selecting independent variables for the logistic regression models using a significance level of 0.05 for a variable to stay in the model. The statistical analysis was carried out with SAS (SAS Institute Inc., Cary, NC, USA) version 9.3 .

\section{Results}

\subsection{Demographics}

Mean age was 47.9 (men 49.6, women 46.6) in 2010, 47.7 (men 49.5, women 46.6) in 2014, and 47.7 (men 48.5, women 47.2) in 2017. The proportion of respondents working in health centers and private sector increased during the study period and respondents from hospitals and other contexts decreased (Table 1) p-values show significance of differences between years). The proportion of the youngest and the oldest age groups and female respondents and the proportion of respondents working in areas with RHIS type 2 increased. (RHIS types defined in Annex 1). Of the EHR systems, the proportion of respondents using EHR-systems ' $a$ ' and ' $b$ ' increased while system ' $h$ ' became less popular. Responses from different hospital districts showed no significant differences between years $(p=0.243)$.

\subsection{Use of paper, RHIS and Kanta by context of use in 2017}

Up to half of the respondents still used paper daily or weekly in 2017 with significant working sector-specific differences (Table 2). RHISs were used daily or weekly mainly in the public health centers, least by users from the private sector, whereas daily or weekly users of

\section{(footnote continued)}

we wanted more precise information about frequency of HIE use by different means. Also Kanta had been introduced, and the old question format did not work anymore. For comparability, an additional variable was built from the 2017 variable, depicting relative use of paper compared to e-means: Respondents, who used paper more frequently than RHIS or Kanta were grouped into "More paper"-users for short. Due to new format of the question statistical differences between the variables 'More paper' and 'Mainly paper' were not calculated. 
Table 1

Demographics of the respondents.

\begin{tabular}{|c|c|c|c|c|}
\hline & 2010 & 2014 & 2017 & $\mathrm{p}$ \\
\hline Target population $\mathrm{N}$ & 14,411 & 16,350 & 17,210 & \\
\hline $\begin{array}{l}\text { Questionnaire sent (\% of target } \\
\text { population) }\end{array}$ & 87 & 91 & 93 & \\
\hline Respondents N & 3,924 & 3775 & 4009 & \\
\hline Gender \% & & & & $<.000$ \\
\hline male & 42.2 & 38.1 & 35.1 & \\
\hline female & 57.8 & 61.9 & 64.9 & \\
\hline Age group \% & & & & $<.000$ \\
\hline-34 & 12 & 16.9 & 16.7 & \\
\hline $35-44$ & 23.6 & 21.2 & 21.9 & \\
\hline $45-54$ & 33 & 28.4 & 26.7 & \\
\hline 55- & 29.1 & 33,6 & 34.7 & \\
\hline Working sector \% & & & & $<.000$ \\
\hline Hospital & 47.3 & 45.1 & 45.2 & \\
\hline Health centre & 24.1 & 24.9 & 25.5 & \\
\hline Private & 12.2 & 12.6 & 15 & \\
\hline Other & 16.4 & 117.3 & 14.3 & \\
\hline Experience in EHR use \% & & & & $<.000^{*}$ \\
\hline Novice & 1.2 & 0.9 & 0.9 & \\
\hline 2 & 7.1 & 4.8 & 3.7 & \\
\hline 3 & 26.5 & 22 & 23.3 & \\
\hline 4 & 42.2 & 45.2 & 41.4 & \\
\hline Very experienced & 23.1 & 27.1 & 30.8 & \\
\hline Means of electronic HIE in use \% & & & & $<.000$ \\
\hline $\begin{array}{l}\text { Type } 1 \text { (Master patient Index) } \\
\text { RHIS + Kanta in } 2017\end{array}$ & 32.4 & 30.1 & 31.5 & \\
\hline $\begin{array}{l}\text { Type } 2 \text { (Virtual regional EHR) } \\
\text { RHIS + Kanta in } 2017\end{array}$ & 14.8 & 16.1 & 19.9 & \\
\hline $\begin{array}{l}\text { Type } 3 \text { (Web distribution) RHIS + Kanta } \\
\text { in } 2017\end{array}$ & 9.9 & 10.1 & 10.8 & \\
\hline Type 4 (multiple) RHIS + Kanta in 2017 & 4.8 & 3.3 & 0 & \\
\hline Type 5 (no) RHIS + Kanta in 2017 & 38.2 & 40.4 & 37.8 & \\
\hline EHR system used \% & & & & $<.000$ \\
\hline System a (Private care) & 0 & 3.3 & 4.7 & \\
\hline System b (Private care) & 9.9 & 11.7 & 12 & \\
\hline System c (Public primary \& special. care) & 25.7 & 24.1 & 25.9 & \\
\hline System d (Public special. care) & 5.7 & 5.4 & 5.8 & \\
\hline System e (Public primary care) & 1.3 & 1.3 & 1.3 & \\
\hline System f (Public primary and special. care) & 4.3 & 3.9 & 5.6 & \\
\hline $\begin{array}{l}\text { System g (Public primary and special. } \\
\text { care) }\end{array}$ & 14.1 & 13.4 & 14.4 & \\
\hline System h (Private care) & 2.7 & 3.1 & 2.1 & \\
\hline System i (Public special. care) & 25.5 & 24.7 & 23.6 & \\
\hline Other systems (j) & 10.8 & 9.7 & 5.7 & \\
\hline
\end{tabular}

EHR (Electronic health record), HIE (Health information exchange), RHIS (Regional health information system), Kanta (National patient data repository).

* Kruskal-Wallis test.

Table 2

Use of paper, RHIS and Kanta by working environment in 2017.

\begin{tabular}{|c|c|c|c|c|c|c|}
\hline & & \multicolumn{4}{|c|}{ Working sector } & \multirow[b]{2}{*}{$\mathrm{p}$} \\
\hline & & Hospital & $\begin{array}{l}\text { Health } \\
\text { centre }\end{array}$ & Private & Other & \\
\hline \multirow[t]{3}{*}{ Using paper } & Total N & 1717 & 967 & 571 & 545 & 0.001 \\
\hline & Daily / weekly \% & 33.9 & 35.5 & 43.1 & 37.6 & \\
\hline & $\begin{array}{l}\text { Less frequently / } \\
\text { not at all } \%\end{array}$ & 66.1 & 64.5 & 56.9 & 62.4 & \\
\hline \multirow[t]{3}{*}{ Using RHIS } & Total N & 1711 & 996 & 510 & 513 & $<.000$ \\
\hline & Daily / weekly \% & 38.1 & 68.3 & 7.7 & 24 & \\
\hline & $\begin{array}{l}\text { Less frequently / } \\
\text { not at all \% }\end{array}$ & 62 & 31.7 & 92.4 & 76 & \\
\hline \multirow[t]{3}{*}{ Using Kanta } & Total N & 1747 & 1005 & 582 & 547 & $<.001$ \\
\hline & Daily / weekly \% & 38.8 & 59.3 & 55.8 & 34.7 & \\
\hline & $\begin{array}{l}\text { Less frequently / } \\
\text { not at all \% }\end{array}$ & 61.2 & 40.7 & 44.2 & 65.3 & \\
\hline
\end{tabular}

RHIS $=$ Regional Health Information System.
Table 3

Main means of HIE, and use of paper by working sector in 2010, 2014 and 2017.

\begin{tabular}{|c|c|c|c|c|c|c|}
\hline Year & 2010 & 2014 & $\mathrm{p}$ & Year & 2017 & $\mathrm{p}$ \\
\hline \multicolumn{3}{|l|}{ Means of HIE \% } & $<.000$ & \multicolumn{3}{|c|}{ Means of HIE \% } \\
\hline $\begin{array}{l}\text { Mainly e- } \\
\text { means }\end{array}$ & 37 & 47 & & $\begin{array}{l}\text { More e- } \\
\text { means }\end{array}$ & 82 & \\
\hline Mainly Paper & 64 & 47 & & More paper & 18 & \\
\hline Total N & 3644 & 3375 & & Total N & 3800 & \\
\hline \multicolumn{3}{|c|}{ Mainly paper / working sector \% } & $<.000$ & $\begin{array}{l}\text { More paper } \\
\text { sector } \%\end{array}$ & working & $<.000$ \\
\hline Hospital & 68 & 47 & & Hospital & 19 & \\
\hline Health centre & 39 & 20 & & $\begin{array}{l}\text { Health } \\
\text { centre }\end{array}$ & 5 & \\
\hline Private & 89 & 87 & & Private & 26 & \\
\hline Other & 68 & 55 & & Other & 31 & \\
\hline Total N & 2259 & 1574 & & Total N & 685 & \\
\hline
\end{tabular}

Kanta were mainly respondents from the public health centers and private sector.

Differences in usage of paper by available RHIS type were significant $(\mathrm{p}<0.001)$ : paper was used daily or weekly most frequently by those with RHIS type 5 in use (42\%), least by those with RHIS type 2 in use (25\%) and by one third of those with RHIS types 1,3 , and 4 in use (37\%, 30\% and 33\% respectively). EHR system 'a' and ' $h$ ' users responded using paper daily or weekly most frequently (53\% and $52 \%$ of respondents respectively) ( $\mathrm{p}<0.001$ ).

\subsection{Evolution of paper use by year, working sector, RHIS system and EHR- system in use}

Between 2010-2014, there was a significant shift from 'mainly paper' to 'mainly electronic' means of HIE (Table 3). The shift was also seen when looking at paper users by working sector, with biggest decreases in paper use among physicians working in hospitals and health centers. In 2017, less than fifth of all respondents reported using 'more paper' than RHIS or Kanta, with significant differences by working sector.

Reduction in 'mainly paper' use from 2010 to 2014 was evident also by RHIS type used, with biggest reduction (from $42 \%$ to $14 \%$ ) in responses from regions using type 2 , and smallest from regions using type 5 RHIS (from 85\% to 74\%). In 2017, significant differences remained: proportions of users of 'more paper' by RHIS types $1-5$ were $18 \%, 6 \%$, $9 \%, 13 \%$, and $25 \%$ respectively ( $\mathrm{p}<0.001$ ).

The proportion of 'mainly paper' users remained very high in 2010-2014 for users of EHR system 'b' (90-86\%), 'd' (79-66\%), ' $h$ ' (83\%-81\%) and 'i' (77\%-62\%). Users of EHR system 'c' (from $39 \%$ to $16 \%$ ), ' $f$ ' (from $75 \%$ to $35 \%$ ), and ' $g$ ' (from $55 \%$ to $29 \%$ ) showed over 20 percentage unit reductions in paper use. For EHR system 'e', the proportion of physicians using mainly paper remained low from 2010 to 2014 (13\% to $2 \%)$. In 2017 , the lowest rates of 'more paper' responses were from users of EHR system 'e' (2\%), 'g' (5\%), 'c' (9\%), and 'd' (13\%), and highest for systems 'h' (39\%), 'i' (27\%), 'f' and 'b' (23\%), with statistically significant differences between systems $(\mathrm{p}<0.001)$. (Annex 3 table 6)

\subsection{Predictors of paper use in 2017}

Access to RHIS types 1 and 5 increased the odds for using 'more paper' than RHIS or Kanta compared to access type 2, controlling for age, gender, working sector, EHR system used, experience in EHR use, and specialty (Table 4). The odds for using more paper than RHIS or Kanta was higher among physicians working in private sector (OR 11.0, 95\% CI 4.8-25.1) and specialized care (OR 1.7, 95\% CI 1.1-2.8) compared to those working in health centers. EHR system 'f' users' odds for using more paper was higher, whereas system 'a', 'b' and ' $\mathrm{g}$ ' users' odds 
Table 4

Predictors of using more paper than RHIS or Kanta in 2017.

\begin{tabular}{|c|c|c|c|}
\hline \multicolumn{4}{|l|}{ Odds Ratio Estimates } \\
\hline Effect & Point Estimate & \multicolumn{2}{|c|}{$\begin{array}{l}\text { 95\% Wald } \\
\text { Confidence Limits }\end{array}$} \\
\hline rhietype 1 vs 2 & 2.1 & 1.3 & 3.4 \\
\hline rhietype 3 vs 2 & 0.9 & 0.4 & 1.8 \\
\hline rhietype 5 vs 2 & 2.1 & 1.3 & 3.5 \\
\hline Age group 2 vs 1 & 1.6 & 1.1 & 2.3 \\
\hline Age group 3 vs 1 & 2.9 & 2.0 & 4.1 \\
\hline Age group 4 vs 1 & 2.8 & 1.9 & 3.9 \\
\hline workings hospital vs health centre & 1.7 & 1.1 & 2.8 \\
\hline workings private vs health centre & 11.0 & 4.8 & 25.1 \\
\hline workings other vs health centre & 4.4 & 2.5 & 7.6 \\
\hline ehr 1 vs 3 & 0.3 & 0.2 & 0.6 \\
\hline ehr 2 vs 3 & 0.2 & 0.1 & 0.5 \\
\hline ehr 4 vs 3 & 1.4 & 0.6 & 3.1 \\
\hline ehr 5 vs 3 & 0.2 & 0.0 & 1.3 \\
\hline ehr 6 vs 3 & 1.9 & 1.2 & 3.2 \\
\hline ehr 7 vs 3 & 0.5 & 0.3 & 0.8 \\
\hline ehr 8 vs 3 & 0.7 & 0.3 & 1.6 \\
\hline ehr 9 vs 3 & 1.5 & 0.9 & 2.5 \\
\hline ehr 10 vs 3 & 0.9 & 0.5 & 1.6 \\
\hline Experience 1 vs 5 & 3.0 & 1.3 & 6.9 \\
\hline Experience 2 vs 5 & 2.2 & 1.4 & 3.5 \\
\hline Experience 3 vs 5 & 1.4 & 1.1 & 1.8 \\
\hline Experience 4 vs 5 & 1.2 & 1.0 & 1.5 \\
\hline Operat vs general & 2.9 & 2.1 & 4.1 \\
\hline Conservat vs general & 1.4 & 1.0 & 2.0 \\
\hline Diagnost vs general & 3.7 & 2.3 & 5.9 \\
\hline Psychiatr vs general & 1.9 & 1.3 & 2.9 \\
\hline Not known vs general & 1.5 & 0.4 & 5.8 \\
\hline Nonspecial vs general & 1.8 & 1.2 & 2.7 \\
\hline male vs female & 1.3 & 1.1 & 1.6 \\
\hline
\end{tabular}

was lower compared to the reference system (system ' $c$ '). The odds for using more paper among physicians working in operative, diagnostic and psychiatric specialties as well as those without specialization was higher compared to physicians working in general medicine specialty. For older physicians and male gender the odds for using more paper was higher. Increase in number of years of using the EHR system decreased the odds.

With 'use of paper daily or weekly' variable as the independent variable, access to RHIS types 1 (OR 1.6, 1.2-2.1) and 5 (OR 1.9, 1.4-2.5) remained as significant predictors. The use of EHR system ' $\mathrm{a}$ ' increased the odds for frequent paper use (OR 1.6, 1.1-2.3).

\section{Discussion}

\subsection{Discussion by key results}

Up to half of the Finnish physicians still used paper for HIE daily or weekly in 2017. This can at least partially be explained by system and data availability: RHISs were not available in all regions, most of the private providers could not access RHISs and all had not joined Kanta. All pertinent patient data are not yet available via Kanta, with up to five days' delay in storing it there, which can be considered too long also in non-urgent cases. Also, daily nursing documentation and medication administration data are not yet stored in Kanta, but are available via RHIS types 2 and 3. In addition, by autumn 2017, only half of patients had given consent to view their data across registrars (https://yle.fi/ uutiset/3-9867258): without consent the data are archived in Kanta, but not disclosed. Trust in privacy has been emphasized in previous literature as prerequisite for HIE [24].

Working sector was a strong predictor of more paper use in 2017 as in our previous study [25]. Availability as well as different HIE needs may explain the result: The largest private providers have patient data documented within the same organization available nationally within the same EHR system. In most hospital districts, physicians have had access to regional radiology and laboratory information systems for nearly two decades, which may reduce the need for viewing RHIS or Kanta in the public sector. Also, pertinent patient information is usually provided in the referral to hospital, sent via point to point connection. Moreover, in cases of inpatient transfers between organizations, information is usually printed to be brought along with the patient. During the hospital stay or consecutive visits to outpatient departments, there is obviously less need for HIE.

Significant differences in paper use by RHIS type and EHR system (cf. [10]) suggest differences in usability of information retrieval as a likely explanation. In the 2010 analysis [9] type 1 predicted lower likelihood of experiencing RHIS support for cross-organizational collaboration and higher likelihood of usability problems, which may explain the higher use of paper in these regions still in 2017 (Types 4 and 5 were not assessed in the earlier analysis). According to previous studies, usability [11-14] and practice setting $[15,16]$ predict usage, and specialty, satisfaction with push HIE, improved access to complete info $[15,18,26]$ predict overall satisfaction with HIE.

The results show great reduction in paper use between 2010 and 2017. Implementation of the national Kanta system after 2014 is the most feasible explanation. It has offered the private sector and regions without RHIS access to patient data across registrars for the first time. However, for physicians who already had access to RHIS, Kanta has offered less added value.

Specialty, age and gender predicted more paper than RHIS or Kanta use in addition to the working sector, HIE access type and EHR system used. Working sector as controlling variable divides respondents also by specialty. Operative, diagnostic and psychiatric specialties as predictors of more paper use may also indicate specialty-specific HIE needs: In operative specialties, relevant information is usually provided in the referral. Diagnostic specialties have dedicated HIE systems (PACS and LIS). In psychiatry, some patients may be more hesitant in giving consent for HIE, however, we found no studies assessing this. Also data of psychiatric patients are in some cases protected with additional access control, which may make its electronic usage more difficult than in other specialties. Operative specialties and psychiatry have been also slower in EHR adaptation than conservative specialties [27-29]. Our finding of males being more likely to use paper for HIE than females is supported by a study showing women being more likely than men to use computers at work [30]. A study on predictors of EHR use showed no gender-specific differences [31]. Age increased the likelihood of using more paper in our study, reducing likelihood of using EHR also in an earlier study [31].

\subsection{Limitations}

Questionnaires are suitable for gathering an overview of a situation and current problem areas from a large group of users. Results don't reveal the causes of problems, but a national survey to users to monitor eHealth policy implementations gives direction to problem solving. Extent of HIE could also be studied using access logs from various HIE systems. However, they do not reveal whether the user actually found the information she/he needed, what proportion of this information was considered useful and what other means for HIE were used. Subjective questionnaires add to our knowledge of actual HIE usage patterns.

The generic survey method reliability and validity questions also apply in this study [32], and were considered when formulating the survey. Three members in our research group were practicing primary and secondary care physicians. This allowed us to fit the questions to respondents' everyday practice, language and understanding of HIE and formulate introductory text.

Selection bias may also occur. In 2010, register information on the physicians' working sector was used to include only physicians working in the clinical work into the target population. In 2014 and 2017, this information was no longer available. Therefore the questionnaires were 
sent to all working aged physicians (i.e. to a larger target population, with a cover letter calling for responses from physicians in clinical work). Based on the results, only physicians working in the clinical work responded the survey each year. Also the register of e-mail addresses was not totally comprehensive, which may have caused additional selection bias.

Grouping respondents by available HIE type was not straightforward: ways that physicians can access data from other organizations and data contents available for them varies, and physicians may not be aware of types of HIE they use. Therefore we used information from an organizational survey for grouping.

We were not able to statistically compare 'mainly paper' variable from 2010 to 2017 due to change in questions. We calculated a proxy variable 'more paper' to serve in the place of 'mainly paper' in the 2017 data, not including it in statistical comparisons.

Questionnaires focus on subjective experiences, which can also be considered an advantage. Previous research shows a strong correlation between user satisfaction of the system, actual usage of it and experienced benefits [33]. A carefully planned questionnaire may offer the respondents unique means of communicating their experiences of ICT usage offering invaluable state-of-the-art data from end-users' viewpoint

\section{Conclusions}

Physicians use paper if they cannot achieve their goals with information systems. Results call for improvements in EHR- and HIEsystem usability to increase usage. Timely access to more complete patient data facilitates safer and more coordinated care of patients. Type 2 RHIS predicted less paper use, providing a good reference point for development.

Results related to specialty- and user-specific differences in HIE pinpoint the urgency to develop deeper understanding of differences in needs and requirements of HIE. Developing information contents of national information services (e.g. Kanta in Finland) for added value to the physicians at point of care across specialties requires more collaboration with users. Attention needs to be paid in older professionals' skills in exploiting the electronic means of HIE.

Summary table

What was known on the topic

- Several countries are implementing regional or national HIE systems.

- Earlier studies have shown rather low use rates: Usability and practice setting predict usage of the HIE

- Preferred means of HIE (paper/ electronic) is associated with the HIE system type, the working sector and the EHR system used

What the study added to the topic

- Frequency of paper use for HIE is still relatively high in 2017 in Finland, although paper use has reduced as the main means of HIE from 2010.

- RHIS type, EHR system, working sector, specialty, age and gender predict paper use.

- Poor usability of electronic HIE and EHR systems are probable causes of HIE and EHR-specific differences.

- Additional analysis is required on speciality-specific needs and factors predicting HIE success.

\section{Authors' contributions}

Hannele Hyppönen, Jarmo Reponen, Tinja Lääveri, Jukka Vänskä and Johanna Kaipio contributed to the questionnaire development, as well as revisions and approval of the manuscript.

Hannele Hyppönen had main responsibility for the manuscript. She was responsible for the study questions, the study outline and main author of the results and discussion. Sonja Lumme acted as the statistician, planning the statistical analyses together with Ms Hyppönen, being responsible of the methods-section, conducting the analyses and co-authoring results.

Jarmo Reponen had the main responsibility for describing the types and functionalities of RHIS systems in Finland and the contextual changes from 2010 to 2017 in Finland, as well as co-authoring discussions.

Johanna Kaipio conducted the search and review of previous literature on the subject. She had main responsibility for the related research chapter. She also participated in modifying other parts of the article.

Tinja Lääveri reviewed the literature together with Johanna Kaipio, acted as a co-author in results and discussion section and checked the overall article for terminology.

\section{Statement on conflicts of interest}

No reported of conflicts of interest.

\section{Acknowledgements}

This study was supported by the Finnish Work Environment Fund (project 116104), the Strategic Research Council (project 303604) and the Ministry of Social Affairs and Health (project 112241). They had no role in the design of the study and collection, analysis, and interpretation of data and in writing. We are grateful to Mark Phillips for proofreading the text. We are also grateful to all clinicians who responded to the survey, as well as all those who helped to develop the survey instrument and commented the results.

\section{Appendix A. Supplementary data}

Supplementary material related to this article can be found, in the online version, at doi:https://doi.org/10.1016/j.ijmedinf.2018.11.005.

\section{References}

[1] S. Hasan, Padman Rema, Analyzing the effect of data quality on the accuracy of clinical decision support systems: a computer simulation approach, AMIA Annu. Symp. Proc. 2006 (2006) 324-328.

[2] J. Adler-Milstein, E. Ronchi, G. Cohen, L.A. Pannella Winn, A.K. Jha, Benchmarking health IT among OECD countries: better data for better policy, J. Am. Med. Inform. Assoc. 21 (1 Jan-Feb) (2014) 111-116.

[3] C.S. Kruse, V. Regier, K. Rheinboldt, Barriers over time to full implementation of health information exchange in the United States, JMIR Med. Inform. 2 (2) (2014) e26.

[4] S. Rahurkar, J.R. Vest, N. Menachemi, Despite the spread of health information exchange, there is little evidence of its impact on cost, use, and quality of care, Health Aff. 34 (March) (2015) 3477-3483.

[5] H. Park, S. Lee, H. Hwang, Y. Kim, E. Heo, J. Kim, et al., Can a health information exchange save healthcare costs? Evidence from a pilot program in South Korea, Int J. Media Inf. Lit. 84 (9) (2015) 658-666.

[6] J. Oderkirk, Readiness of Electronic Health Record Systems to Contribute to National Health Information and Research. OECD Health Working Papers, No. 99, OECD Publishing, Paris, 2017.

[7] Act on Electronic prescription 61/2007] Laki sähköisestä lääkemääräyksestä 61/ 2007, Finlex, Available from https://www.finlex.fi/fi/laki/ajantasa/2007/ 20070061, (Accessed 29 August 2018).

[8] Government proposal for the Parliament on electronic handling of client data in social and health care HE 253/2006 Hallituksen esitys Eduskunnalle sosiaali- ja terveydenhuollon asiakastietojen sähköistä käsittelyä koskevaksi lainsäädännöksi HE 253/2006, Finlex, https://www.finlex.fi/fi/esitykset/he/2006/20060253, Available from (Accessed 29 August 2018).

[9] H. Hyppönen, J. Reponen, T. Lääveri, J. Kaipio, User experiences of different 
regional health information exchange systems in Finland, Int. J. Med. Inform. 83 (1) (2014) 1-18.

[10] C. Gadd, Y. Ho, C. Cala, D. Blakemore, Q. Chen, M. Frisse, et al., User perspectives on the usability of a regional health information exchange, J. Am. Med. Inform. Assoc. 18 (September, October (5)) (2011) 711-716.

[11] P. Hsieh, Physicians' acceptance of electronic medical records exchange: an extension of the decomposed TPB model with institutional trust and perceived risk, Int. J. Media Inf. Lit. 84 (1) (2015) 1-14.

[12] V. Patel, E.L. Abramson, A. Edwards, S. Malhotra, R. Kaushal, Physicians' potential use and preferences related to health information exchange, Int. J. Media Inf. Lit. 80 (3) (2011) 171-180.

[13] E. Tham, S. Ross, B. Mellis, B. Beaty, L. Schilling, A. Davidson, Interest in health information exchange in ambulatory care: a statewide survey, Appl. Clin. Inform. 31 (February (1)) (2010) 1-10.

[14] S. Lee, H. Park, J. Kim, H. Hwang, E. Cho, Y. Kim, et al., Physicians' perceptions and use of a health information exchange: a pilot program in South Korea, Telemed. J E Health 18 (October (8)) (2012) 604-612.

[15] T.J. Campion, J. Ancker, A. Edwards, V. Patel, R. Kaushal, Push and pull: physician usage of and satisfaction with health information exchange, AMIA Annu. Symp. Proc. 2012 (2012) 77-84.

[16] F.X. Campion, J.M. Richter, High-level adoption of electronic health records, J. Med. Pract. Manage.: MPM 27 (1) (2011) 50-56.

[17] P. Esmaeilzadeh, M. Sambasivan, Health Information Exchange (HIE): a literature review, assimilation pattern and a proposed classification for a new policy approach, J. Biomed. Inform. 64 (December) (2016) 74-86.

[18] K. Kuhn, F. Lau, Evaluation of a shared electronic health record, Healthc. Q. 17 (1) (2014) 30-35.

[19] J. Vänskä, J. Viitanen, H. Hyppönen, M. Elovainio, I. Winblad, J. Reponen, et al., Lääkärien arviot potilastietojärjestelmistä kriittisiä, Suomen lääkärilehti - Finlands läkartidning 65 (50-52) (2010) 4177-4183.

[20] J. Vänskä, S. Vainiomäki, J. Kaipio, H. Hyppönen, J. Reponen, T. Lääveri, Electronic Patient Record Systems as physician's tools in 2014: no significant changes in user experience, Suomen Lääkärilehti (2014) 3351-3358 49/2014 vsk 69.

[21] J. Viitanen, H. Hypponen, T. Laaveri, J. Vanska, J. Reponen, I. Winblad, Nationa questionnaire study on clinical ICT systems proofs: physicians suffer from poor usability, Int. J. Med. Inform. 80 (10) (2011) 725.

[22] J. Kaipio, T. Lääveri, H. Hyppönen, A. Kushniruk, S. Vainiomäki, J. Reponen, E. Borycki, Usability problems do not heal by themselves: national survey on physicians' experiences with EHRs in Finland, Int. J. Med. Inform. 97 (January) (2017) 266-281.

[23] J. Reponen, M. Kangas, P. Hämäläinen, N. Keränen, Use of information and communications technology in Finnish health care in 2014. Current situation and trends, Tieto- ja viestintäteknologian käyttö terveydenhuollossa vuonna 2014, Tilanne ja kehityksen suunta. Raportti 2015/12, Terveyden ja hyvinvoinnin laitos, Helsinki, 2018.

[24] J.S. Ancker, A.M. Edwards, M.C. Miller, R. Kaushal, Consumer perceptions of electronic health information exchange, Am. J. Prev. Med. 43 (1) (2012) 76-80.

[25] F.X. Campion, J.M. Richter, High-level adoption of electronic health records, J. Med. Pract. Manage. 27 (1) (2011) 50-56.

[26] S.A. Thorn, M.A. Carter, J.E. Bailey, Emergency physicians' perspectives on their use of health information exchange, Ann. Emerg. Med. 63 (March (3)) (2014) 329.

[27] J. Reponen, I. Winblad, P. Hämäläinen, Current status of national eHealth and telemedicine development in Finland, Stud. Health Tech. Inf. 134 (2008) 199-208.

[28] H. Hyppönen, P. Hämäläinen, J. Reponen (Eds.), e-Health and e-Welfare of Finland. Check Point, Report 2015/18. Helsinki: National Institute for health and welfare., 2015.

[29] P. Hämäläinen, J. Reponen, I. Winblad, J. Kärki, M. Laaksonen, H. Hyppönen, et al., eHealth and eWelfare of Finland. Checkpoint, National Institute for health and welfare, Helsinki, 2011 Report 2013/5.

[30] NTIA, A Nation Online: How Americans Are Expanding Their Use of the Internet, U.S. Department of Commerce. National Telecommunications and Information Administration (NTIA), Washington, DC, 2002, pp. 1-98.

[31] N. Menachemi, R.G. Brooks, EHR and other IT adoption among physicians: results of a large-scale statewide analysis, J. Healthc. Inform. Manage. JHIM 20 (3) (2006) 79.

[32] A.C. Scherpenzeel, W.E. Saris, The validity and reliability of survey questions: a meta analysis of MTMM studies, Sociol. Methods Res. 25 (3) (1997) 341-383.

[33] W.H.M.E.R. DeLone, The DeLone and McLean model of information systems success: a ten-year update, J. Manag. Inf. Syst. 19 (Spring (4)) (2003) 30. 